NBER WORKING PAPER SERIES

\title{
DOES INCREASED ACCESS INCREASE EQUALITY? GENDER AND CHILD HEALTH INVESTMENTS IN INDIA
}

\author{
Emily Oster \\ Working Paper 12743 \\ http://www.nber.org/papers/w12743

\section{NATIONAL BUREAU OF ECONOMIC RESEARCH \\ 1050 Massachusetts Avenue \\ Cambridge, MA 02138} \\ December 2006
}

Gary Becker, Kerwin Charles, Steve Cicala, Amy Finkelstein, Andrew Francis, Jon Guryan, Matthew Gentzkow, Lawrence Katz, Michael Kremer, Steven Levitt, Kevin Murphy, Jesse Shapiro, Andrei Shleifer, Rebecca Thornton, and participants in seminars at Harvard University, the University of Chicago, and NBER provided helpful comments. I am grateful for funding from the Belfer Center, Kennedy School of Government. Laura Cervantes provided outstanding research assistance. The views expressed herein are those of the author(s) and do not necessarily reflect the views of the National Bureau of Economic Research.

(C) 2006 by Emily Oster. All rights reserved. Short sections of text, not to exceed two paragraphs, may be quoted without explicit permission provided that full credit, including $\odot$ notice, is given to the source. 
Does Increased Access Increase Equality? Gender and Child Health Investments in India Emily Oster

NBER Working Paper No. 12743

December 2006

JEL No. I18,J13,J16,O12

\begin{abstract}
$\underline{\text { ABSTRACT }}$
Policymakers often argue that increasing access to health care is one crucial avenue for decreasing gender inequality in the developing world. Although this is generally true in the cross section, time series evidence does not always point to the same conclusion. This paper analyzes the relationship between access to child health investments and gender inequality in those health investments in India. A simple theory of gender-biased parental investment suggests that gender inequality may actually be non-monotonically related to access to health investments. At low levels of availability, investment in girls and boys is low but equal; as availability increases, boys get investments first, creating inequality. As availability increases further, girls also receive investments and equality is restored. I test this theory using data on the relationship between gender balance in vaccinations and the availability of "Health Camps" in India. I find support for a non-monotonic relationship. This result may shed light on the contrast between the cross-sectional and time-series evidence on gender and development, and may provide guidance for health policy in developing countries.
\end{abstract}

\author{
Emily Oster \\ University of Chicago \\ Graduate School of Business \\ 5807 South Woodlawn Avenue \\ Chicago, IL 60637 \\ and NBER \\ eoster@post.harvard.edu
}


Report focused on equity, with gender equity as a central issue (World Bank, 2006). Further, decreases in the female-male sex ratio (number of women divided by number of men) over time in India, South Korea, China and elsewhere - whether due to sex-selective abortion or other changes - have raised concerns about the consequences of this trend for societies (Hudson and den Boer (2004)).

Policy makers have argued that increasing the level of development is one of the key factors in ameliorating gender inequality. In 2001, a World Bank report on gender and development begins with the statement that poverty and gender inequality are closely linked: "Large gender disparities in basic human rights, in resources and economic opportunity ... are pervasive around the world ... And these disparities are inextricably linked to poverty," (World Bank, 2001). One of the aspects of development cited as crucial to affecting gender inequality is access to health services (World Bank, 1991; Hill and Upchurch, 1995). It has been argued that increasing the level of health care will benefit women and reduce gender inequality (Grown, Gupta and Pande, 2005), although the link between development and inequality is not limited to health (see, for example, Duflo, 2005). This argument is particularly salient in India, where poverty is often linked to gender ratios by region and, by extension, to excess female mortality (World Bank, 1991; Chatterjee, 1990).

These conclusions are largely motivated by the cross-country relationship between gender inequality and development: gender inequality is highest in poor countries. The poverty-inequality relationship is not, however, always supported in the time-series data. Figure 1, for example, shows the female-male sex ratio (number of women in the population divided by number of men) in India over the twentieth century. Although India has had a dramatic increase in income over this period, the population has become increasingly male-dominated $!^{1}$ In this paper I think carefully about the relationship between access and inequality and argue that, both in theory and in fact, improvements in health inputs may have ambiguous effects on gender inequality.

In this paper I focus on the case of India, and explore the relationship between gender inequality and access to health investments in that country. I begin in Section 2 by presenting

\footnotetext{
${ }^{1}$ This pattern is even more surprising when we consider that as life expectancy overall increases we would generally expect the sex ratio to increase since women tend to live longer.
} 
a simple model of gender-biased parental investment in which parents choose whether or not to invest in health care for their children. The model assumes that this care is costly, but has positive effects on survival. The model suggests that the effect of access to health care on gender inequality is non-monotonic. In particular, starting from a situation with little access (equivalently, high costs), increases in access will increase inequality. Continued increases in access, however, will eventually reduce inequality. Intuitively, when health care is first made available (but is expensive) the most valuable children - i.e., boys - will get access to it first. This means that there is some range of increasing access where more boys are getting health care while there is no change for girls, making the gender imbalance worse. Further improvements in access, however, will lead to a decrease in the gender imbalance as the society moves to a situation in which all children are given the same care..$^{2}$

I test this prediction in the context of vaccinations. I argue in Oster (2006) that excess female mortality in childhood is by far the most important driver of the overall gender imbalance in India. $3^{3}$ The results in that paper also suggest that gender differences in vaccination are an important factor in explaining excess female mortality in childhood, explaining somewhere between 20 percent and 30 percent of the mortality differences. Taken together, these facts suggest that gender differences in child vaccination rates may drive up to a quarter of the total population gender imbalance in India. Understanding which policies might affect vaccination rates may go a long way toward changing overall gender imbalances in survival in India.4

The primary test of the theoretical prediction relies on variation in the availability of "Health Camps" in Indian villages. The availability of these camps increases access to

\footnotetext{
${ }^{2}$ There are interesting parallels between this theoretical result and an older literature on wealth and intrahousehold inequality. Kanbur and Haddad (1994), for example, argue that an intrahousehold bargaining framework can predict this type of non-monotonic relationship between wealth and inequality within the household.

${ }^{3}$ This is distinct from differences in mortality in adulthood or differences that arise prior to birth. The latter category would include hepatitis B, which I have argued elsewhere (Oster, 2005) is responsible for around 20 percent of the (historical) gender imbalance in India, as parents who are carriers of the hepatitis B virus are more likely to have male children.

${ }^{4}$ This issue of proximate causes of excess female mortality is distinct from a large literature on underlying causes of gender inequality - female education, labor force participation, etc (see, for example, Rosenzweig and Shultz, 1982; Agnihotri, 2000; Agnihotri et al., 2002; Murthi et al., 1995; Rahman and Rao, 2004). However, it is related to a smaller but still substantial literature on the proximate causes of mortality (Das Gupta, 1987; Basu, 1989; Griffiths et al., 2000; Borooah, 2004; Pande, 2003; Mishra et al., 2004). That literature argues for many different proximate causes (health care, nutrition) of which vaccination rates are one.
} 
vaccination. I argue that the placement of these camps is unrelated to existing vaccination conditions, income, education, or average number of children. Consistent with institutional details, camp concentration does vary by state, as well as with village population and distance to health clinics. These are observable variations, which can ( and will) be controlled for extensively.

Section 4 presents evidence that, consistent with the theory, initial increases in the number of camps increase the gender imbalance in vaccination, but that further increases decrease the imbalance. As further support for the theory, I find that this non-monotonic effect is stronger for families with a stronger reported gender bias and somewhat stronger in areas where other sources of vaccination are further away. In Section 5 , I discuss two alternative tests of the non-monotonic prediction, relying on information on distance to other vaccination sources and regional-level variation in vaccination levels.

In the final section of the paper, I consider whether this non-monotonicity is reflected in changes in mortality over time. I first use retrospective information on child mortality from the microdata to construct a short panel of child mortality over the period from 1982-1993. Consistent with the theory, excess female mortality increases over this period in areas where initial vaccination levels are low. However, during the same period, excess female mortality decreases in areas with initially high levels of vaccination. I then explore whether there is any evidence for this non-monotonicity in mortality differences over a longer period of time in India. Using data on life expectancy by gender in India for the last one hundred years, I show that while average life expectancy increases, women initially lose years relative to men and then rebound. It is obvious that this type of non-monotonicity is not driven by vaccinations alone, suggesting that non-monotonicities in other investments may have influenced changes in the sex ratio over time.

The results in this paper may be informative about policy. In particular, the results suggest that how vaccinations (and possibly other health inputs) are introduced to developing areas may be meaningful. A program that puts two vaccination camps in every village may have a similar overall effect as one that puts four camps in half of the villages, but the impact on gender inequality is likely to be quite different. Ultimately, the policy choice depends on whether we are concerned only about overall mortality or whether the gender imbalance is a 
direct input to the social utility function.

\section{Theory of Parental Investment}

This section analyzes a simple model of gender-biased parental investments in children. The question of interest here is how increases in access to health investments will affect the gender equality in those same investments. The later empirical work in this paper will focus on a particular investment, vaccination, which is discrete. The theory also focuses on discrete investments.

Families have either a male or a female child, with measure 1 of each type of family. There is a unitary family utility function, which is separable over money and children. The utility of a girl is $\phi_{g}$ and of a boy is $\phi_{b}$. In this model, boys are preferred, so $\phi_{b}>\phi_{g} !^{5}$ For simplicity, I will assume that utility of income is linear. The overall utility function for each family type is therefore:

$$
\begin{aligned}
U_{g} & =Y+\phi_{g} \\
U_{b} & =Y+\phi_{b}
\end{aligned}
$$

Parents have an opportunity to invest in a health input for their children. Without this input, a child will live with probability $p$. With the input, they live with probability $\hat{p}>p$. The cost of this health input for family $i$ is $v+\varepsilon_{i}$, where $\varepsilon \sim N\left(0, \sigma^{2}\right)$. For ease of explication, I focus on the special case of normally distributed costs. However, the central conclusion holds true for a wider set of distributions. In Appendix A, I discuss general results.

The health input will be chosen for boys and girls, respectively, if the following inequalities hold.

$$
\begin{aligned}
& \phi_{b}(\hat{p}-p)-v>\varepsilon_{i} \\
& \phi_{g}(\hat{p}-p)-v>\varepsilon_{i}
\end{aligned}
$$

\footnotetext{
${ }^{5}$ The assumption of one child families is obviously a simplification. However, it is not crucial. In an earlier version of this paper (available from the author), I developed a version of the model in which families were endowed with existing boy and girl children. In that model, I find that discrimination against girls is predicted to decrease with the number of existing male children and increase with the number of existing female children. However, the results on access (below) hold as long as, on average, boys are preferred to girls. Note that this can hold even if the only reason girls are discriminated against is that they are in larger families.
} 
The share of boys invested in is, therefore, $F\left(\phi_{b}(\hat{p}-p)-v\right)$ and the share of girls is $F\left(\phi_{g}(\hat{p}-p)-v\right)$, where $F($.$) is distributed normally. The gender inequality in investment is$ measured by the difference in these shares: $F\left(\phi_{b}(\hat{p}-p)-v\right)-F\left(\phi_{g}(\hat{p}-p)-v\right)$. The analysis focuses on the change in this quantity as $v$ changes $\sqrt[6]{7}$

Denote the gender difference $\Theta$. Under the assumption of normally distributed costs, this difference is simply

$$
\Theta=\int_{\phi_{g}(\hat{p}-p)-v}^{\phi_{b}(\hat{p}-p)-v} \frac{1}{\sqrt{2 \pi \sigma^{2}}} \exp \left(\frac{-(x)^{2}}{2 \sigma^{2}}\right) d x
$$

Integrating out, and differentiating with respect to $v$ implies that

$$
\frac{d \Theta}{d v}=\frac{1}{\sqrt{2 \pi \sigma^{2}}}\left(-\exp \left(\frac{-\left(\phi_{b}(\hat{p}-p)-v\right)^{2}}{2 \sigma^{2}}\right)+\exp \left(\frac{-\left(\phi_{g}(\hat{p}-p)-v\right)^{2}}{2 \sigma^{2}}\right)\right)
$$

The sign of this differential, however, changes based on $v$. The result is summarized in Proposition 1.

Proposition 1. When investment costs are high on average, decreases in the cost result in increased pro-male bias. As average investment costs decrease, the sign of this effect switches and further decreases result in decreases in gender bias.

Proof. The proposition claims that $\frac{d D}{d v}$ is negative for high $v$ and positive for low $v$ and moves from negative to positive as $v$ decreases. To prove, I show a sufficient set of conditions:

$\frac{d D}{d v}>0$ when $v=0, \frac{d D}{d v}<0$ when $v=\infty$, and $\frac{d D}{d v}$ is decreasing everywhere as $v$ increases. To show this, note that the derivative suggests that $\frac{d D}{d v}<0$ when

$\left(\phi_{b}(\hat{p}-p)-v\right)^{2}-\left(\phi_{g}(\hat{p}-p)-v\right)^{2}<0$. When $v=0,\left(\phi_{b}(\hat{p}-p)\right)^{2}-\left(\phi_{g}(\hat{p}-p)\right)^{2}>0$, so $\frac{d D}{d v}>0$. When $v=\infty$, the difference is negative, so $\frac{d D}{d v}<0$. Differentiating with respect to $v$, we find that the object is decreasing when $-2 \phi_{b}+2 \phi_{g}<0$, which will hold everywhere since $\phi_{b}>\phi_{g}$.

The proposition suggests that, beginning in a situation with very high investment costs (hence, limited investments), increases in access will make gender inequality worse. Further increases, however, are predicted to decrease gender inequality.

To see the graphical intuition behind the result, consider Figure 2. This figure graphs two possible cost distributions with different levels of $v$; the dotted line represents a

\footnotetext{
${ }^{6}$ To see why this is the quantity of interest, consider that the overall sex ratio (given equal shares of boys and girls born) is equal to $\frac{p+(\hat{p}-p) F\left(\phi_{b}(\hat{p}-p)-v\right)}{p+(\hat{p}-p) F\left(\phi_{g}(\hat{p}-p)-v\right)}$. As $F_{b}-F_{g}$ increases, this will increase; as it decreases, this will decrease. The difference between the two therefore maps into the ultimate object of interest, which is the sex ratio.
} 
distribution with better access to the health investment (lower $v$ ). The cutoffs $W_{1}, M_{1}$ and $W_{2}, M_{2}$ represent two sets of investment cutoffs ( $W_{x}$ is the cutoff for women, $M_{x}$ for men). The mass of the distribution under the cutoff receives the investment, so the $W_{1}, M_{1}$ cutoffs represent a world with overall higher investment levels. Consider what happens to the gender difference in investments when we move from the solid to the dotted distribution, which represents a decrease in $v$. For the case of $W_{2}, M_{2}$, this movement causes a greater increase in the share receiving the investment for men than for women because both lines are on the increasing part of the distribution. In contrast for the case of $W_{1}, M_{1}$, the increase causes a greater improvement for women because both lines are on the decreasing part of the distribution. It is this intuition that is central to the result.

In Appendix A, I discuss the generality of this result. Although it will not be true for all cost distributions, the intuition in Figure 2 is robust. In particular, the fact that $\frac{d D}{d v}$ is negative at high values of $v$ and positive at low values will be true in general for any single peaked distributions (although it will hold for other distributions, as well). If we take this framework seriously, it suggests that improvements in access to health care are not always the path to decreased gender inequality, at least in the short run.

\section{Data}

The analysis here is run using individual-level microdata on child health investments in India. I use primarily the second wave of the National Family and Health Survey (NFHS), which covers approximately 90,000 women and was run in 1998-1999. Women are asked about their birth history, including children ever born, dates of birth, if the children are alive, and, if not, when they died. In addition, for children under four, information is collected on vaccination and other health inputs. I will also make some use of the earlier wave of the NFHS, which was run on a similar sample size in 1992-1993.

The primary child investment analyzed here is vaccination. There are seven possible vaccinations: three DPT (diphtheria, pertussis, and tetanus) vaccines, two polio vaccines, a measles vaccine, and a BCG (tuberculosis) vaccine. The measure of vaccination is simply the total number of vaccinations reported on the child's health card. The results are extremely 
similar if I consider the determinants of each vaccination separately.

The analysis will also use information on the number of "Family Health and Welfare Camps" held in each village in the previous year, as well as information on distance to other sources of vaccination. The information on camps is drawn from the NFHS village survey (administered to the village head). The information on distance is household-specific and comes from the NFHS household survey.

\section{Health Camps and Gender Differences in Vaccination}

This section describes the primary test of the theory in this paper, which relies on variation in the availability of vaccination camps across villages. In the first subsection I discuss the placement of vaccination camps. The second subsection presents results.

\subsection{Placement of Health Camps}

Beginning in the mid-1990s, the National Health and Welfare Ministry in India began a new phase of the overall campaign to bring better health care to India - the Reproductive and Child Health Programme (RCH) (Indian Ministry of Health and Family Welfare, 1998). One of the primary elements of this campaign is greater outreach remote and poorly served areas. This outreach comes primarily in the form of establishing Primary Health Centers (PHC) and Community Health Centers (CHC) to serve relatively small population areas. These centers, in turn, can run RCH camps, either in their own location or in even more remote areas. In contrast to the PHC and $\mathrm{CHC}$, these camps are mobile and temporary, usually lasting only one or two days, and offer only very basic health services (for a general discussion of these camps, see Mavalankar and Sinha, 1999).

There appears to be no systematic scheme for camp placement. The RCH programme is run at the state level, suggesting that there may well be variations across states in the number of camps. In addition, since the camps were based out of PHCs and CHCs and travel is expensive, we may expect areas closer to these clinics to have more camps. Finally, village population may also have a role, since the benefit of a camp is likely to be larger in bigger villages. Given these concerns, all regressions will allow for the effect of gender to differ 
between states and in interaction with village population and distance to these other sources of health care.

However, it is also important to consider whether empirical placement of the camps appears to be non-random beyond these controls. For example, are there more camps in richer or more well-educated areas, or areas with more children? To test for this, in Table 1, I regress the number of camps by village on some simple village characteristics (income, maternal education and age, village population, and ideal sex ratio) from the 1998 survey. $!^{7}$

In the first column, I simply show the regression on village size, distance to another source, and state fixed effects (the coefficients on state are not shown, but the test that they are all equal is reported). As suspected, all three of these parameters matter - there are more camps in larger villages and in those villages closer to a $\mathrm{PHC}$ or $\mathrm{CHC}$. In addition, we can reject the equality of the coefficients for each state with high confidence. Column 2 of Table 1 includes a set of additional demographic controls. None of these additional controls are significant; placement does not seem to be related to education, income, age, religion, or number of children. This is also true if we do not condition on state, population, and distance (results available from the author).

A more specific concern is that camp placement might be correlated with initial vaccination conditions. However, it is not possible to examine this possibility using the 1998 data since we expect causality to run the other way (more camps imply more vaccination). To test for a relationship between vaccination camp placement and pre-existing gender differentials in vaccinations, I take advantage of the 1992 wave of the survey: Table 2 estimates the relationship between the average number of camps (at the state level) and gender difference in vaccination rates in 1992. Column 1 includes the gender difference in vaccination and average vaccinations linearly; column 2 includes a quadratic in each. This regression suggests no relationship between the gender difference in vaccination and camp placement. This suggests that although there were important state-specific drivers of the number of camps, these do not seem to be related to gender imbalances in vaccination. It would be better to link the surveys in smaller geographic units, but the data does not provide

\footnotetext{
${ }^{7}$ In this case, and throughout this section, the number of camps is top-coded at five. Ninety-eight percent of villages have five or fewer camps, and the top-coding avoids allowing outliers to drive the results.
} 
consistent links between districts over time.

This discussion should provide some confidence that, although placement of these camps is by no means completely exogenous, the primary drivers of the placement can be observed and I control for them. It is also the case that, even if these camps were placed endogenously (for example, targeting areas with low vaccination levels), the endogenaity would have to be of a particular form in order to induce the non-linear results seen here. Targeting areas with low vaccinations would not produce these results. Targeted camp placement could drive the results only if areas with high male preference were targeted to receive a few camps, while areas with low male preference were targeted to receive either no camps or many camps. Although it is obviously not possible to rule this out, it would seem like a relatively unusual circumstance.

\subsection{Results on Camps and Gender Inequality}

The central question in this section is how the gender imbalance in vaccination is related to the number of health camps. The basic result can be seen in Figure 3, which reports the gender difference in average number of vaccinations for children six months to two years, graphed against the number of vaccination camps in the previous year, as well as the average number of vaccinations for each gender $\square^{8}$ The figure points to a non-monotonic relationship. Moving from zero or one camp to two camps causes a large increase in the gender difference. This increase continues up to three camps, after which girls begin to gain again. The maximum gender difference is at three camps, and the gender difference is similar at zero or one camp, and at five or more. Of course, the average number of vaccinations is generally increasing for both boys and girls as the number of camps increase, so children are, on average, better off in areas with four or five camps than areas with none.

Table 3 explores the relationship in a regression context with controls. I control for standard demographics and family characteristics. In addition, all regressions include state fixed effects and interactions between state and gender dummies, as well as interactions between gender and quadratics of both village population and distance to the nearest $\mathrm{PHC}$ or

\footnotetext{
${ }^{8}$ I restrict to children in this age group since they are the ones who would have needed vaccinations in the previous year. Consistent with this, the results are less strong for older children.
} 
CHC. All standard errors are clustered at the village level. Column 1 assumes that the relationship between vaccination camps and gender imbalance is quadratic and estimates the coefficient on the interaction between girl and number of camps and the interaction between girl and the number of camps squared (as before, the number of camps is top-coded at five). The coefficient estimates do point to a non-monotonic relationship. The linear interaction term is negative (increases in vaccination camps increase discrimination), but the squared term is positive. The magnitudes suggest that the effect is zero around 4.2 vaccination camps per year.

In Columns 2 and 3 of Table 3, I consider an alternative to the assumption of a quadratic functional form. I estimate the regression separately for areas with few camps and areas with many. Column 2 estimates the effect of vaccination camps in areas with fewer than three camps, and Column 3 estimates the effects in areas with more than three camps. The results are consistent with Column 1. In areas with limited vaccination camps, increases seem to make girls worse off relative to boys. In areas with more camps, increases improve the relative position of girls..$^{9}$ Interestingly, the (relative) negative effect of initially increasing access is more significant than the (relative) positive effect of further increases. This may reflect the much smaller sample size, but it could also suggest that the catch-up effect is more limited, particularly at the number of camps we are considering here.

Despite the evidence in the previous subsection that the placement of camps is unrelated to village-level socioeconomic status, there may still be concerns about these issues. Column 4 of Table 3 therefore replicates Column 1 but also includes controls for the interaction between gender and income, gender and income squared, and gender and education (linear and squared), as well as the existing controls for gender interactions with village population and distance. If the result on vaccination camps is being driven by some non-linear interaction of gender and another control, this specification should identify it. In fact, the coefficients in Column 4 are extremely similar to Column 1, suggesting that these issues are not responsible for the results.

\footnotetext{
${ }^{9}$ The magnitude of the interaction, relative to the level effect of camps, would suggest that initial increases in vaccination camps actually make girls worse off in an absolute sense, which is not consistent with the pattern in Figure 4. This is due to the inclusion of state fixed effects and the gender interaction with state; these inclusions make the level effect of camps impossible to interpret.
} 
One of the assumptions underlying the theoretical framework is that boys are preferred to girls. This assumption, however, provides an additional prediction - namely, the non-linear effect should be stronger for people who have a stronger preference for male children. To test this, I divide the sample based on each woman's reported ideal sex ratio and replicate the regression in Column 1 of Table 3 for each half of the sample. The hypothesis is that the non-linearity should be stronger for the set of women who report wanting a greater ratio of boys to girls ${ }^{10}$ I define women as having a preference for boys if they report wanting more boys than girls; the alternative is desiring equal numbers or more girls.

These regressions are shown in Columns 1 and 2 of Table 4 . Column 1 includes women who do not want a male-biased sex ratio among children; Column 2 includes those who do. The results are consistent with the theory. In Column 1, neither of the two interactions between gender and camps is significant. In Column 2, however, the interactions are significant and much larger. The contrast suggests that, as predicted, this relationship holds more consistently for families with more gender-biased preferences. In Columns 3 and 4 of Table 4, I replicate this analysis but divide families based on the average desired gender composition in their area (primary sampling unit). This is, perhaps, a weaker test than the one using individual preferences. However, it does avoid the issue that parental gender preferences may be related to the gender of their existing children. The results in Columns 3 and 4 look very similar to those in Columns 1 and 2. In areas with limited male-biased preferences, neither coefficient is significant, whereas in areas with stronger male-biased preferences, both coefficients are significant.

A second sample split-based test of the theory relies on the observation that vaccination camps are not the only way children get vaccinated. The non-monotonicity should therefore be stronger in areas where vaccination camps are more important. In the NFHS, women who have a young child are asked where most of the child's vaccinations of the child took place. The majority of women report either a Primary Health Center (PHC), a Community Health Center (CHC), or a Government Hospital. For women with easy access to

\footnotetext{
${ }^{10}$ Obviously, reported ideal number of male and female children is not a perfect measure of gender preferences. However, it should provide some proxy. In addition, it is certainly the case that the gender inequality in vaccination is larger for families where parents report wanting more male children (results available from the author).
} 
these sources, it seems likely that vaccination camps will be less important.

This analysis is complicated somewhat by the fact that, as noted, camps are more likely in villages where a $\mathrm{PHC}$ or $\mathrm{CHC}$ is located. This means that it may be the case that people who live in a village with one of these sources are more likely to rely on camps than people who live just outside of them. Although the comparison of people who live near the source versus far is still valid, this may dampen the results. I divide the sample into three groups based on distance to the closest PHC, CHC, or Government Hospital - less than five $\mathrm{km}$ away, five-ten $\mathrm{km}$ away, and more than ten $\mathrm{km}$ away. The regression results are shown in Table 5. Consistent with the importance of camps, the non-monotonicity is strongest in areas that are more than $10 \mathrm{~km}$ away. Although the coefficients in Columns 1 and 2 are not significant, the coefficients in Column 1 (for areas very close to a PHC, CHC, or hospital) are slightly larger. This may be driven by the relationship between distance and camps.

Both Tables 4 and 5 bolster the conclusions in Table 3 . The effect of vaccination camps is largest for families with limited access to other sources of vaccination and for those with stronger male-biased preferences. Another obvious test would be to explore whether the inequality-access relationship holds less strongly for families where there are two children of opposite gender close in age. Intuitively, in families where a female child needs vaccination at the same time as a male child, the relationship between access and inequality may be muted. Unfortunately, the sample sizes are too limited (given the necessary closeness in age - a year or less) to test this hypothesis.

\section{Other Determinants of Vaccination Access}

A significant advantage of the analysis above is that vaccination camps are likely to operate in large part as shocks to the availability of vaccination in the village. This makes them less obviously correlated with existing conditions and they provide a relatively clean test. In addition, their discrete nature makes the exploration of non-monotonic effects relatively straightforward. The theoretical framework, however, is not specific to vaccination camps (or even to vaccination). In general, we expect discrimination to be non-monotonic in any measure of access to vaccination. This section considers two alternative proxies for access to 
vaccination and aims to demonstrate, among other things, that the results are not driven by the use of health camps as the shifter of access.

I first proxy for access using the reported distance from the nearest Primary Health Center, Community Health Center, or Government Hospital, as reported in the village survey in the 1998 NFHS. Approximately 50 percent of women report this as their source of immunization, so it seems to be a good proxy for access. Of course, access to these centers has other implications and may be correlated with unobservables. However, there is no obviously apparent bias that would produce a non-monotonic relationship in gender imbalance.

Table 6 shows the relationship between total vaccinations and gender, interacted with both distance and distance squared. In this case, the theory would predict the interaction with distance to be negative and with distance squared to be positive ${ }^{11}$ A sizable fraction of people report having a health facility in their village. These are coded as zero distance, although this may not be strictly correct.

In Column 1 of Table 6, I show the regression with all observations; in Column 2, I restrict to people who report a non-zero distance to avoid any issues with the in-village measure. The coefficients have the expected sign and are at least marginally significant in both columns. If anything, the results are stronger in Column 2, when I leave out people who report having a health facility in their village. The relationship switches sign at a distance of around $30 \mathrm{~km}$. Columns 3 and 4 of Table 6 split the entire sample based on gender preferences (as was done in Table 4). Column 3 shows the regression for women who report wanting more girls or wanting equality; Column 4 shows the regression for women who report wanting more boys. Again, as expected, the results are much stronger for those with a male-biased preference.

As a second test, I consider the cross-regional relationship between the level of vaccination and the gender difference in vaccination. In this case, the level of vaccination is the proxy for vaccination access. Even more than the analysis with Primary and Community Health Centers, this is subject to bias. However, it does provide the only opportunity to consider this relationship outside of rural villages.

\footnotetext{
${ }^{11}$ These predicted interactions have the opposite sign from the interactions on number of camps because increases in the number of camps imply increases in access and increases in distance imply decreases in access.
} 
I take advantage of the cluster design of the NFHS (a cluster, in this case, is a collection of on average 750 households in the same area). I aggregate the data to the cluster level and calculate the average number of vaccinations and the difference between this average for boys and girls. The primary regression will consider the shape of the relationship between the level and the difference. The results are shown in Table 7 , where the dependent variable is the gender difference in average number of vaccines received; Column 1 considers a monotonic relationship between the level and the difference, and Column 2 considers a non-monotonic relationship. The results seem consistent with a nonlinear relationship; the coefficient in Column 1 is small, and not significant. In Column 2, however, both the average and the average squared are significant and have the expected sign. The number of vaccinations ranges from zero to seven. The magnitude of the coefficients suggests that the gender imbalance is increasing up to an average of five vaccinations and decreasing thereafter 12

\section{Non-Monotonicities in Mortality over Time}

The evidence in the previous two sections focuses on vaccination directly. However, the theoretical framework is not specific to vaccinations, or even to childhood illnesses. If the theory holds true more broadly, that would suggest non-monotonicities in movements in mortality over time. In this section, I consider some evidence on changes in mortality over time. This evidence is much more preliminary and speculative than the evidence on vaccinations. The first subsection discusses mortality among children; the second takes a broader view and considers overall life expectancy in India over time.

\subsection{Childhood Mortality, 1982-1993}

Given the focus on child health investments above, it seems reasonable to first consider non-monotonic changes in gender inequality in childhood mortality. Ideally, we would like to have a relatively long time-series in which child mortality by gender is observed. These type

\footnotetext{
${ }^{12}$ This result is in contrast to the results in Pande and Yazbeck (2003), who argue that gender differences in immunization across states do not seem to be related to levels. This may underscore the importance of considering the regional relationship at a less aggregated level.
} 
of data are not generally available. It is possible, however, to create a short time series using retrospective reports on child mortality in the two survey waves of the NFHS.

I consider the mortality outcomes for children born between five and ten years before each survey year (1992 and 1998). This effectively creates a time series of child death rates from 1982 through 1993. The outcome of interest is mortality between 18 months and five years. I do not consider very early life mortality, since it will be generally unaffected by investments like vaccinations. In addition, I limit to children under the age of ten to avoid (as much as possible) the chance that mothers have forgotten to list children who were born many years ago and died early in life.

The ideal analysis would look at the existence of non-monotonic changes in the gender balance of mortality over time within a particular area. Unfortunately, with such a short time series, there are no areas that have gone through a sufficiently large change. Instead, I consider whether the change in the gender imbalance in mortality over this short period is different in regions with different initial levels of vaccination.

Using information on average number of vaccinations by state in 1992 and 1998 surveys, I first restrict the analysis to states in which there was an increase of at least 0.1 vaccinations between the two survey years ${ }^{13}$ I then divide the remaining states into two groups based on their initial level of vaccination and using information from Figure 3 on the level of vaccination at which the relationship flips sign. There are relatively few areas with many vaccinations, and I restrict this group to states where the average number of vaccinations by 1998 is at least three (Tripura, Jammu, Himachal Pradesh, Kerala, and Goa) 14 All remaining states are assigned to the other group. Recall that the theory would suggest increases in relative female mortality in areas with initially low vaccinations and decreases in areas with initially high levels.

The results from the regressions for the two groups are shown in Table 8. Column 1

\footnotetext{
${ }^{13}$ This eliminates Rajasthan, Bihar, Uttar Pradesh, Haryana, Gujarat, Arunachal Pradesh, Assam, New Delhi, and Mizoram.

${ }^{14}$ The evidence from Figure 3 would suggest that the cutoff is higher than this. However, what we observe in Figure 3 is the average vaccination level after the vaccination clinics. Presumably the vaccination level was lower before, making three a reasonable cutoff. In addition, because this is done at the state level (due to the fact that I cannot link smaller areas in the data over time), there are virtually no states with very high levels of vaccination. It is worth noting that these issues will only make it more difficult to find evidence of non-monotonicities.
} 
shows the regression in the low initial vaccination group and Column 2 in the high vaccination group. The coefficient of interest is on the interaction between girl and date of birth. The dependent variable is an indicator for having died between 18 months and five years, so the theory suggests a positive coefficient in Column 1 and a negative coefficient in Column 2. In addition to the simple demographic controls shown, I have included birth order dummies and dummies for each region, as well as for these regional dummies interacted with gender. This controls for the possibility that low (or high) levels of vaccination are correlated with overall levels of gender discrimination.

The results in Table 8 are supportive of the theory. In Column 1, the coefficient on the interaction is positive. The magnitude suggests that during the ten-year period considered, female mortality in these regions increased relative to male mortality by 0.74 percentage points. In contrast, the coefficient in Column 2 is negative. During the same ten-year period, female mortality in those regions decreased relative to male mortality by 0.96 percentage points. These are both quite large effects since the average mortality in this age range is around 3 percent.

\subsection{Life Expectancy in India, 1870-2000}

Given the effects on child mortality, it is interesting to consider whether it is possible to see these non-monotonicities in wider data - in particular, in data on life expectancy in India over the previous century. This moves away from the earlier analysis in two respects. First, life expectancy and child mortality are not identical, although they are be closely linked, since a major component of increases in life expectancy from initially low levels is decreases in infant mortality. Second, the issue of vaccinations is important later in the century, but not in the early part. The analysis here looks for a more general correlation between level of health investments and the gender difference in mortality. Evidence for such a relationship might suggest that there are non-monotonicities across genders in other health investments.

The Indian Census (formerly the British Census of India) reports life expectancy for men and women over the period from 1871 to the present. Using these data, it is possible to construct time series of the average life expectancy and the difference between genders in life expectancy for this relatively long period. These series are graphed in Figure 4. In these data, 
particularly after 1910, we see evidence of a U-shaped relationship in the difference, accompanied by an overall increase in the average (the general pattern of changes for men and women over the century is very similar). In the 1910-1920 period, female life expectancy exceeds that of men by around 1.5 years, although the average is very low, at around 20. By the 1960-1970 period, female life expectancy is actually 1.5 years less than that of men, but the average has increased to around 45. Women seem to rebound by the end of the period. Women in 1980-1990 have a life expectancy about 1 year greater than men, and the average has climbed to almost 60 years.

This may shed some light on overall changes in the sex ratio in India over the previous one hundred years. It is well known that population female-male sex ratios (the ratio of women to men in the population) have been falling over time. This is consistent with increases in discrimination, but it is also potentially consistent with a constant level of discrimination and the non-monotonic effect discussed above. The evidence on life expectancy in Figure 4 would suggest that, if this is true, the sex ratio in the population should not continue to decline, but should rebound toward the end of the century. ${ }^{15}$ Interestingly, as can be seen in Figure 1, we do see some evidence of a potential rebound, or at least a flattening of the trend after 1970, and some increase between 1990 and 2000. The timing is similar to the trend in life expectancies.

The drop in sex ratio over time has caused significant policy concern (Mayer, 1999). The graphs here may not demonstrate that changes over time are necessarily related to non-monotonic changes in the gender imbalance in health investments. However, taken together with the evidence on vaccinations, the connection is suggestive. If true, it may lead us to expect further changes in the patterns of mortality over time, with sex ratios trending back toward a situation where the imbalance is similar to what it was at the start of the century, but the level of mortality is much lower.

\footnotetext{
${ }^{15}$ This ignores the introduction of sex-selective abortion, which has become increasingly important recently (see Jha et al., 2006).
} 


\section{Conclusion}

There has been much policy focus, particularly in India, on increasing access to health services as a means of decreasing gender inequality. This paper explores the evidence supporting such interventions. I argue that increasing access to vaccination is an obvious intervention of this type, since vaccination is an important input to child health. However, both theory and evidence indicate that the effects of increases in access to vaccinations are not clear. At low levels of immunization, increasing access is likely to make the gender imbalance worse, while further increases are likely to improve the imbalance.

The analysis above is primarily positive. I focus on establishing the relationship between vaccination availability and gender imbalance. This leads to the question of whether there are normative conclusions to be made. Do these results suggest a particular policy approach?

It is worth noting, first, that technological change, in the form of sex-selective abortion, may increasingly render this issue moot. It has been recently argued that as many as 10 million female fetuses were aborted in the last fifteen years (Jha et al., 2006). In the limit, if use of this technology increases, it could be the case that virtually all discrimination is moved to the period before birth. In this case, conditional on being born, there should be limited discrimination and we should see no non-monotonic effect of increases in vaccination access. This scenario seems unlikely, in part because Indian authorities have moved to prevent increases in the use of these technologies and in part because abortion may not be less costly than neglect. Nevertheless, it may temper any possible policy ramifications here.

Abstracting away from recent changes, the potential policy conclusions here depend largely on what welfare function we hope to maximize. These results suggest that increases in access to health inputs will make everyone better off; they just make girls better off more slowly than boys. If the primary concern is decreasing mortality, then a policy that seeks to increase access to health investments may be optimal. If, on the other hand, the policymaker cares independently about the sex ratio, then it may be prudent to think more carefully about the mechanics of health interventions.

To be more concrete, the non-monotonicity would suggest that if policymakers care 
directly about the sex ratio, interventions to increase access to health inputs should focus on saturating one area rather than introducing the inputs in a more limited way in all areas. If we take the quantitative results in this paper seriously, it is possible to directly evaluate these tradeoffs. In particular, combining the results implicit in Figure 3 with the effect of vaccination estimated elsewhere (Oster, 2006) can tell us the effect of different methods of vaccination camp dispersion. Consider the difference between moving from zero to three camps in all areas of the country, versus moving from zero to some kind of saturation (i.e. at least four) in half of the regions. The calibration suggests that moving from zero to three camps in all areas would increase survival by, on average, ten lives per 10,000 children. However, it would increase the sex ratio by eleven for every 20,000 children. In contrast, moving from zero to saturation in half the regions would also increase survival, on average (including non-affected areas), by ten lives per 10,000, while leaving the sex ratio unchanged. Which of these two options to choose will depend largely on the preferences of policymakers, or the social welfare function. If gender discrimination is paramount, then introducing many camps into a few areas is ideal. On the other hand, if spatial or regional discrimination takes priority, there may be an argument for equal introduction everywhere, despite the consequences for gender ratios. 


\section{Appendix A: General Theoretical Results}

This appendix discusses the general form of the result in Section 2. As there, we note that the conditions for vaccinations for boys and girls are

$$
\begin{aligned}
& \phi_{b}(\hat{p}-p)-v>\varepsilon_{i} \\
& \phi_{g}(\hat{p}-p)-v>\varepsilon_{i}
\end{aligned}
$$

and that the difference of interest is $F\left(\phi_{b}(\hat{p}-p)-v\right)-F\left(\phi_{g}(\hat{p}-p)-v\right)$. In the text I focus on the case where $F($.$) is normal and show results indicating that at high v$ this difference will increase with decreases in $v$, and at low $v$ the difference will decrease with decreases in $v$. Here, I discuss what must generally be true about the distribution for this to hold.

This difference $\Theta$ can be represented

$$
\Theta=\int_{\phi_{g}(\hat{p}-p)}^{\phi_{b}(\hat{p}-p)} f(x-v) d x
$$

Differentiating this with respect to $v$ yields:

$$
\frac{d \Theta}{d v}=-\int_{\phi_{g}(\hat{p}-p)}^{\phi_{b}(\hat{p}-p)} f^{\prime}(x-v) d x
$$

In order for this to be negative at high $v$ and positive at low $v$, we simply require that $f($.$) be$ increasing in the left tail, and decreasing in the right tail. Any single-peaked distribution will have this property.

In contrast to the case of the normal, where this is decreasing everywhere in $v$, we will not be able to prove that generally. However, the intuition that girls become relatively worse off with decreases in $v$ at high $v$ and relatively better off with decreases in $v$ at low $v$ will be true for a wide class of distributions. 


\section{References}

Agnihotri, Satish, Sex Ratio Patterns in the Indian Population: A Fresh Exploration, New Delhi, India: Sage, 2000.

, Richard Palmer-Jones, and Ashok Parikh, "Missing Women in Indian Districts: A Quantitative Analysis," Structural Change and Economic Dynamics, 2002, 13, 285-314.

Basu, Alaka, "Is Discrimination in Food Really Necessary for Explaining Sex Differentials in Childhood Mortality?," Population Studies, 1989, 43 (2), 193-210.

Borooah, Vani, "Gender bias among children in India in their diet and immunisation against disease," Social Science and Medicine, 2004, 58, 1719-1731.

Chatterjeee, Meera, "Indian Women: Health and Productivity," Policy, Research and External Affairs Working Paper Series, 1990, (442).

Das Gupta, Monica, "Selective Discrimination Against Female Children in Rural Punjab, India," Population and Development Review, 1987, 13 (1), 77-100.

Duflo, Esther, "Gender Equality in Development," 2005. MIT Working Paper.

Griffiths, Paula, Zoe Matthews, and Andrew Hinde, "Understanding the Sex Ratio in India: A Simulation Approach," Demography, 2000, 37 (4), 477-488.

Grown, Caren, Geeta Rao Gupta, and Rohini Pande, "Taking Action to Improve Women's Health Through Gender Equality and Women's Empowerment," The Lancet, 2005, 365, 541-543.

Hill, Kenneth and Dawn Upchurch, "Gender Differences in Child Health: Evidence from Demographic and Health Surveys," Population and Development Review, 1995, 21 (1), $127-151$.

Hudson, Valerie and Andrea den Boer, Bare Branches, Cambridge, MA: The MIT Press, 2004.

Indian Ministry of Health and Family Welfare, Annual Report, New Delhi, India: Govt. of India, Ministry of Health and Family Welfare, 1998.

Jha, Prabhat, Rajesh Kumar, Priya Vasa, Neeraj Dhingra, Deva Thiruchelvam, and Rahim Moineddin, "Low male-to-female sex ratio of children born in India: National Survey of 1.1 Million Households," Lancet, 2006, 367, 211-218.

Kanbur, Ravi and Lawrence Haddad, "Are Better Off Households More Unequal or Less Unequal," Oxford Economic Papers, 1994, 46, 455-468.

Mavalankar, D.V. and Harshit Sinha, "Reproductive Health Camps: An Innovative Approach to Integrating Reproductive Health Intervention into Primary Health Care," 1999. Indian Institute of Management Working Paper. 
Mayer, Peter, "India's Falling Sex Ratios," Population and Development Review, 1999, 25 (2), 323-340.

Mishra, Vinad, T.K. Roy, and Robert Retherford, "Sex Differentials in Childhood Feeding, Health Care, and Nutritional Status in India," Population and Development Review, 2004, 30 (2), 269-295.

Murthi, Anne-Catherine Guio Mamta and Jean Dreze, "Mortality, Fertility and Gender Bias in India: A District Level Analysis," Population and Development Review, 1995, 21 (4), 745-782.

Oster, Emily, "Hepatitis B and the Case of the Missing Women," Journal of Political Economy, 2005, 113 (6), 1163-1215.

_ _ "Proximate Causes of Population Gender Imbalance in India," 2006. Mimeo, University of Chicago.

Pande, Rohini, "Selective gender differences in childhood nutrition and immunization in rural India: The role of siblings," Demography, 2003, 40 (3), 395-418.

— and Abdo Yazbeck, "Whats in a country average? Wealth,gender,and regional inequalities in immunization in India," Social Science and Medicine, 2003, 57, 2075-2088.

Rahman, Lupin and Vijayendra Rao, "The Determinants of Gender Equity in India: Examining Dyson and Moore's Thesis with New Data," Population and Development Review, 2004, 30 (2), 239-268.

Rosenzweig, Mark and T. Paul Shultz, "Market Opportunities, Genetic Endowments and Intrafamily Resource Distribution: Child Survival in India," American Economic Review, 1982, 72 (4), 803-815.

Sen, Amartya, "Missing Women," British Medical Journal, 1992, 304, 587-588.

_ , "More than 100 Million Women are Missing," New York Review of Books, December 20, 1990.

World Bank, Gender and Poverty in India: A World Bank Country Study, Washington, DC: World Bank, 1991.

__ , "Engendering Development," Technical Report, World Bank 2001.

— , World Development Report: Equity and Development, Washington DC: World Bank and Oxford University Press, 2006. 
Table 1. Vaccination Camps and Current Village Characteristics

\begin{tabular}{|c|c|c|}
\hline \multicolumn{3}{|c|}{ Dependent Variable: Number of Camps } \\
\hline & (1) & $(2)$ \\
\hline \multicolumn{3}{|l|}{ Explanatory } \\
\hline \multicolumn{3}{|l|}{ Variables: } \\
\hline Village Population & $\begin{array}{l}.5542^{* * *} \\
(7.15)\end{array}$ & $\begin{array}{l}.5372^{* * *} \\
(6.75)\end{array}$ \\
\hline Distance to Other Source & $\begin{array}{l}-.0072^{* *} \\
(-2.1)\end{array}$ & $\begin{array}{l}-.0073^{* *} \\
(-2.03)\end{array}$ \\
\hline Ave Mother Educ & & $\begin{array}{l}-.0045 \\
(-.29)\end{array}$ \\
\hline Ave. Mother Age & & $\begin{array}{l}.0144 \\
(1.06)\end{array}$ \\
\hline Ave. \# Durables & & $\begin{array}{l}.0371 \\
(.75)\end{array}$ \\
\hline Ave. Ideal Sex Ratio & & $\begin{array}{l}.4278 \\
(1.06)\end{array}$ \\
\hline Ave. \# Kids & & $\begin{array}{l}.0024 \\
(.06)\end{array}$ \\
\hline Share Hindu & & $\begin{array}{l}.0583 \\
(.55)\end{array}$ \\
\hline constant & $\begin{array}{l}.669^{* * *} \\
(15.15)\end{array}$ & $\begin{array}{l}.186 \\
(.61)\end{array}$ \\
\hline State Fixed Effects & YES & YES \\
\hline F-Stat, State FE Equal & 7.66 & 6.83 \\
\hline Number of Observations & 2335 & 2248 \\
\hline $\mathrm{R}^{2}$ & .19 & .18 \\
\hline \multicolumn{3}{|c|}{$\begin{array}{l}\text { Notes: This table estimates whether there is evidence that camp placement is based } \\
\text { on current village characteristics. An observation is a village, and the dependent } \\
\text { variable is the average number of camps. } \\
\text { t-statistics in parentheses } \\
{ }^{*} \text { significant at } 10 \% ;{ }^{* *} \text { significant at } 5 \%{ }^{* * *} \text { significant at } 1 \%\end{array}$} \\
\hline
\end{tabular}


Table 2. Camps and 1992 State Characteristics

\begin{tabular}{|c|c|c|}
\hline \multicolumn{3}{|c|}{ Dependent Variable: Ave. Number of Camps (by State) } \\
\hline & $(1)$ & $(2)$ \\
\hline \multicolumn{3}{|l|}{ Explanatory } \\
\hline \multicolumn{3}{|l|}{ Variables: } \\
\hline \multirow[t]{2}{*}{ Gender Diff in Vacc, 1992} & .2075 & -.3692 \\
\hline & $(.2)$ & $(-.17)$ \\
\hline \multirow[t]{2}{*}{ Average Vacc, 1992} & -.3558 & .7254 \\
\hline & $(-.95)$ & $(.52)$ \\
\hline \multirow{2}{*}{ Gender Diff in Vacc, 1992, Sq. } & & -2.0194 \\
\hline & & $(-.49)$ \\
\hline \multirow{2}{*}{ Average Vacc, 1992, Sq. } & & -.2263 \\
\hline & & \\
\hline \multirow[t]{2}{*}{ Ave. Income (Durables) } & -.5047 & -.0547 \\
\hline & $(-1.03)$ & $(-.09)$ \\
\hline \multirow[t]{2}{*}{ Ave. Mother's Educ } & -.1524 & -.0879 \\
\hline & $(-1.01)$ & $(-.53)$ \\
\hline \multirow[t]{2}{*}{ Total Kids } & $-1.3281^{* * *}$ & -1.2485 \\
\hline & $(-2.99)$ & $(-2.67)$ \\
\hline \multirow[t]{2}{*}{ constant } & $8.369^{* * *}$ & $6.578^{*}$ \\
\hline & $(3.23)$ & $(1.92)$ \\
\hline Number of Observations & 25 & 25 \\
\hline $\mathrm{R}^{2}$ & .36 & .42 \\
\hline \multicolumn{3}{|c|}{$\begin{array}{l}\text { Notes: The table estimates whether there is any evidence for camp placement being } \\
\text { based on existing gender differences in vaccination. An observation is a state and } \\
\text { the dependent variable is the average number of camps. The independent variable } \\
\text { of interest is the difference in vaccination rates across genders in that state in } 1992 \text {. } \\
\text { t-statistics in parentheses } \\
{ }^{*} \text { significant at } 10 \% ;{ }^{* *} \text { significant at } 5 \%{ }^{* * *} \text { significant at } 1 \%\end{array}$} \\
\hline
\end{tabular}


Table 3. Vaccination Camps and Gender Imbalance in Vaccination

\begin{tabular}{|c|c|c|c|c|}
\hline \multicolumn{5}{|c|}{ Dependent Variable: Number of Vaccinations Child Has } \\
\hline & $(1)$ & $(2)$ & $(3)$ & (4) \\
\hline & Entire Sample & $<3$ Camps & $\geq 3$ Camps & Sample \\
\hline \multicolumn{5}{|l|}{ Explanatory } \\
\hline \multicolumn{5}{|l|}{ Variables: } \\
\hline Girl × \# Camps & $\begin{array}{l}-.2183^{* *} \\
(-2.5)\end{array}$ & $\begin{array}{l}-.1442^{* *} \\
(-2.27)\end{array}$ & $\begin{array}{l}.2553^{*} \\
(1.76)\end{array}$ & $\begin{array}{l}-.22^{* *} \\
(-2.51)\end{array}$ \\
\hline Girl $\times$ \# Camps Sq. & $\begin{array}{l}.0447^{* *} \\
(2.2)\end{array}$ & & & $\begin{array}{l}.0446^{* *} \\
(2.2)\end{array}$ \\
\hline \# Camps & $\begin{array}{l}.0881 \\
(1.24)\end{array}$ & $\begin{array}{l}.0321 \\
(.59)\end{array}$ & $\begin{array}{l}-.1152 \\
(-1.17)\end{array}$ & $\begin{array}{l}.0904 \\
(1.27)\end{array}$ \\
\hline \# Camps Sq. & $\begin{array}{l}-.0156 \\
(-.98)\end{array}$ & & & $\begin{array}{l}-.0165 \\
(-1.04)\end{array}$ \\
\hline Child Age & $\begin{array}{l}1.69^{* * *} \\
(6.61)\end{array}$ & $\begin{array}{l}1.6321^{* * *} \\
(5.99)\end{array}$ & $\begin{array}{l}2.066^{* * *} \\
(2.78)\end{array}$ & $\begin{array}{l}1.669^{* * *} \\
(6.54)\end{array}$ \\
\hline Child Age Sq. & $\begin{array}{l}-.5487^{* * *} \\
(-5.35)\end{array}$ & $\begin{array}{l}-.5293^{* * *} \\
(-4.83)\end{array}$ & $\begin{array}{l}-.671^{* *} \\
(-2.28)\end{array}$ & $\begin{array}{l}-.543^{* *} \\
(-5.30)\end{array}$ \\
\hline \# Older brothers & $\begin{array}{l}-.0162 \\
(-.45)\end{array}$ & $\begin{array}{l}-.0064 \\
(-.17)\end{array}$ & $\begin{array}{l}-.0873 \\
(-.87)\end{array}$ & $\begin{array}{l}-.0170 \\
(-.47)\end{array}$ \\
\hline \# Older Sisters & $\begin{array}{l}.0445^{* *} \\
(2.53)\end{array}$ & $\begin{array}{l}.0435^{* *} \\
(2.29)\end{array}$ & $\begin{array}{l}.0479 \\
(1.07)\end{array}$ & $\begin{array}{l}.0393^{* *} \\
(2.23)\end{array}$ \\
\hline State Fixed Effects & YES & YES & YES & YES \\
\hline State-Gender Inter. & YES & YES & YES & YES \\
\hline Village Size-Gender Inter. & YES & YES & YES & YES \\
\hline Distance-Gender Inter. & YES & YES & YES & YES \\
\hline Gender-Control Inter. & $\mathrm{NO}$ & $\mathrm{NO}$ & NO & YES \\
\hline Number of Observations & 10,854 & 9,415 & 1,439 & 10,577 \\
\hline $\mathrm{R}^{2}$ & .29 & .29 & .29 & .29 \\
\hline \multicolumn{5}{|c|}{$\begin{array}{l}\text { Notes: This table estimates the effect of vaccination camps on the gender imbalance in vac- } \\
\text { cination. An observation is a child aged six months to two years and the dependent variable } \\
\text { is the number of vaccinations the child has received (0-7). \# Camps is the number of Family } \\
\text { Health and Welfare Camps reported in the village in the previous year }-0,1,2,3,4 \text { or } 5 \\
\text { or more. Column } 1 \text { includes all areas. Column } 2 \text { includes only areas where the number of } \\
\text { camps is } 0,1 \text { or } 2 \text {. Column } 3 \text { includes only areas in which there are three or more camps. All } \\
\text { columns include interactions between gender and state, as well as interactions between gender } \\
\text { and village population (linear and squared) and distance to closest CHC or PHC (linear and } \\
\text { squared). Column } 4 \text { also includes interactions between gender and income (linear and squared) } \\
\text { and education (linear and squared). The main effect of girl is subsumed in the state-gender } \\
\text { interactions. Other controls: maternal age, maternal education, family durable ownership, a } \\
\text { dummy for being Hindu, birth order and village size. } \\
\text { t-statistics in parentheses, standard errors clustered at the village level } \\
{ }^{*} \text { significant at } 10 \%{ }^{* *} \text { significant at } 5 \% \text {; }{ }^{* * *} \text { significant at } 1 \%\end{array}$} \\
\hline
\end{tabular}


Table 4. Effect of Vaccination Camps by Gender Preference

\begin{tabular}{|c|c|c|c|c|}
\hline \multicolumn{5}{|c|}{ Dependent Variable: Number of Vaccinations Child Has } \\
\hline & $(1)$ & $(2)$ & $(3)$ & (4) \\
\hline & $\begin{array}{c}\text { Ideal: } \\
\text { Equal/More Girls }\end{array}$ & $\begin{array}{c}\text { Ideal: } \\
\text { More Boys }\end{array}$ & $\begin{array}{l}\text { Ave. Ideal: } \\
\text { Girls }\end{array}$ & $\begin{array}{c}\text { Ave Ideal: } \\
\text { Boys }\end{array}$ \\
\hline \multicolumn{5}{|l|}{ Explanatory } \\
\hline \multicolumn{5}{|l|}{ Variables: } \\
\hline \multirow{2}{*}{ Girl × \# Camps } & -.1199 & $-.3101^{* *}$ & -.1441 & $-.2846^{* *}$ \\
\hline & $(-1.08)$ & $(-2.11)$ & $(-1.28)$ & $(-2.08)$ \\
\hline \multirow{2}{*}{ Girl × \# Camps Sq. } & .0214 & $.065^{*}$ & .0241 & $.063^{* *}$ \\
\hline & & $(1.92)$ & & \\
\hline \multirow[t]{2}{*}{ \# Camps } & .0351 & .1483 & .0659 & .0815 \\
\hline & $(.41)$ & $(1.43)$ & $(.72)$ & $(.74)$ \\
\hline \multirow[t]{2}{*}{ \# Camps Squared } & -.0004 & -.0326 & -.0112 & -.0138 \\
\hline & $(-.02)$ & $(-1.42)$ & $(-.55)$ & $(-.58)$ \\
\hline \multirow[t]{2}{*}{ Child Age } & $1.3506^{* * *}$ & $2.2676^{* * *}$ & $1.6469^{* * *}$ & $1.8098^{* * *}$ \\
\hline & $(4.24)$ & $(5.84)$ & $(4.64)$ & $(4.89)$ \\
\hline \multirow[t]{2}{*}{ Child Age Sq. } & $-.4246^{* * *}$ & $-.7657^{* * *}$ & $-.5395^{* * *}$ & $-.5882^{* * *}$ \\
\hline & $(-3.32)$ & $(-4.84)$ & $(-3.8)$ & $(-3.93)$ \\
\hline \multirow{2}{*}{ \# Older Brothers } & -.0108 & .012 & .012 & -.0363 \\
\hline & $(-.21)$ & $(.24)$ & $(.2)$ & $(-.83)$ \\
\hline \multirow{2}{*}{ \# Older Sisters } & $.083^{* * *}$ & $.0531^{* *}$ & $.0727^{* * *}$ & .0206 \\
\hline & $(2.91)$ & $(2.18)$ & $(2.72)$ & $(.85)$ \\
\hline State Fixed Effects & YES & YES & YES & YES \\
\hline State-Gender Inter. & YES & YES & YES & YES \\
\hline Village Size-Gender Inter. & YES & YES & YES & YES \\
\hline Distance-Gender Inter. & YES & YES & YES & YES \\
\hline Number of Obs. & 6267 & 4292 & 5761 & 4796 \\
\hline $\mathrm{R}^{2}$ & .29 & .24 & .29 & .29 \\
\hline \multicolumn{5}{|c|}{$\begin{array}{l}\text { Notes: This table estimates the effect of vaccination camps on the gender imbalance in vaccina- } \\
\text { tion. An observation is a child aged six months to two years and the dependent variable is the } \\
\text { number of vaccinations the child has received (0-7). \# Camps is the number of Family Health } \\
\text { and Welfare Camps reported in the village in the previous year. All columns include interac- } \\
\text { tions between gender and state, as well as interactions between gender and village population } \\
\text { (linear and squared) and distance to closest CHC or PHC (linear and squared). Column } 1 \text { in- } \\
\text { cludes only women who report wanting equal numbers of boys and girls or more girls; Column } \\
2 \text { includes women who report wanting more boys. Column } 3 \text { includes areas in the bottom } 50 \% \\
\text { in average desired boys; Column } 4 \text { includes areas in the top } 50 \% \text {. Other controls: maternal } \\
\text { age, maternal education, family income, a dummy for being Hindu, birth order, a quadratic in } \\
\text { child age. } \\
\text { t-statistics in parentheses, standard errors clustered at the village level } \\
{ }^{*} \text { significant at } 10 \% ;{ }^{* *} \text { significant at } 5 \% ; * * * \text { significant at } 1 \%\end{array}$} \\
\hline
\end{tabular}


Table 5. Effect of Vaccination Camps by Distance to Other Source

\begin{tabular}{|c|c|c|c|}
\hline \multicolumn{4}{|c|}{ Dependent Variable: Number of Vaccinations Child Has } \\
\hline & $(1)$ & $(2)$ & (3) \\
\hline & Other Source $<5 \mathrm{~km}$ & Other $5-10 \mathrm{~km}$ & Other $>10 \mathrm{~km}$ \\
\hline \multicolumn{4}{|l|}{ Explanatory } \\
\hline \multicolumn{4}{|l|}{ Variables: } \\
\hline \multirow[t]{2}{*}{ Girl × \# Camps } & -.1791 & -.1228 & $-.3169^{*}$ \\
\hline & $(-1.45)$ & $(-.67)$ & $(-1.76)$ \\
\hline \multirow{2}{*}{ Girl $\times$ \# Camps Sq. } & .036 & .0058 & $.079^{* *}$ \\
\hline & (1.29) & $(.13)$ & $(2.01)$ \\
\hline \multirow{2}{*}{ \# Camps } & .0261 & $2648^{*}$ & -.0218 \\
\hline & $(.27)$ & $(1.81)$ & $(-.13)$ \\
\hline \multirow[t]{2}{*}{ \# Camps Squared } & 0017 & -.0435 & -.0038 \\
\hline & $(.08)$ & $(-1.25)$ & $(-.11)$ \\
\hline \multirow{2}{*}{ Child Age } & $1.5034^{* * *}$ & $1.4172^{* * *}$ & $2.2335^{* * *}$ \\
\hline & $(3.97)$ & $(2.85)$ & $(4.61)$ \\
\hline \multirow[t]{2}{*}{ Child Age Sq. } & $-.5038^{* * *}$ & $-.4001^{* *}$ & $-.7484^{* * *}$ \\
\hline & $(-3.31)$ & $(-2.01)$ & $(-3.87)$ \\
\hline \multirow{2}{*}{ \# Older Brothers } & .0003 & -.0919 & .028 \\
\hline & $(.01)$ & $(-1.33)$ & $(.41)$ \\
\hline \multirow[t]{2}{*}{ \# Older Sisters } & 0354 & .0396 & 0516 \\
\hline & $(1.29)$ & $(1.22)$ & $(1.54)$ \\
\hline State Fixed Effects & YES & YES & YES \\
\hline State-Gender Inter. & YES & YES & YES \\
\hline Village Size-Gender Inter. & YES & YES & YES \\
\hline Number of Obs. & 4998 & 2851 & 2728 \\
\hline $\mathrm{R}^{2}$ & .29 & .32 & .28 \\
\hline \multicolumn{4}{|c|}{$\begin{array}{l}\text { Notes: This table estimates the effect of vaccination camps on the gender imbalance in vac- } \\
\text { cination. An observation is a child aged } 6 \text { months to } 2 \text { years and the dependent variable is } \\
\text { the number of vaccinations the child has received }(0-7) \text {. \# Camps is the number of Family } \\
\text { Health and Welfare Camps reported in the village in the previous year. All columns include } \\
\text { interactions between gender and state, as well as interactions between gender and village popu- } \\
\text { lation (linear and squared). Column } 1 \text { includes people who report a CHC, PHC, or Government } \\
\text { Hospital within } 5 \mathrm{~km} \text { of their house; Column } 2 \text { includes those who report one between } 5 \text { and } \\
10 \mathrm{~km} \text { away and Column } 3 \text { includes those who report the nearest of these is more than } 10 \mathrm{~km} \\
\text { away. Other controls: maternal age, maternal education, family income, a dummy for being } \\
\text { Hindu, birth order, a quadratic in child age. } \\
\text { t-statistics in parentheses, standard errors clustered at the village level } \\
{ }^{*} \text { significant at } 10 \% \text {; }{ }^{* *} \text { significant at } 5 \% ; * * \text { significant at } 1 \%\end{array}$} \\
\hline
\end{tabular}


Table 6. Access to Health Facility and Gender Imbalance in Vaccination

\begin{tabular}{|c|c|c|c|c|}
\hline \multicolumn{5}{|c|}{ Dependent Variable: Number of Vaccinations Child Has } \\
\hline & $(1)$ & $(2)$ & $(3)$ & (4) \\
\hline & All & Not in Village & Ideal: Equal/Girls & Ideal: Boys \\
\hline \multicolumn{5}{|l|}{ Explanatory } \\
\hline \multicolumn{5}{|l|}{ Variables: } \\
\hline \multirow[t]{2}{*}{ Girl $\times$ Dist. } & $-.0181^{* *}$ & $-.0245^{* *}$ & -.0142 & $-.0281^{* *}$ \\
\hline & $(-2)$ & $(-2.25)$ & $(-1.18)$ & $(-2.02)$ \\
\hline \multirow{2}{*}{ Girl $\times$ Dist. Sq. } & $.0005^{* *}$ & $.0006^{* *}$ & .0004 & $.0008^{* *}$ \\
\hline & $(2.16)$ & (2.47) & $(1.14)$ & (2.39) \\
\hline \multirow{2}{*}{ Distance } & -.0122 & -.0139 & -.0146 & -.0066 \\
\hline & $(-1.6)$ & $(-1.5)$ & $(-1.54)$ & $(-.67)$ \\
\hline \multirow[t]{2}{*}{ Dist. Sq. } & -.0001 & -.0001 & & -.0002 \\
\hline & $(-.62)$ & $(-.27)$ & $(-.18)$ & $(-1.07)$ \\
\hline \multirow[t]{2}{*}{ Child Age } & .241 & .3172 & .3812 & .0329 \\
\hline & $(1.1)$ & $(1.28)$ & $(1.33)$ & $(.1)$ \\
\hline \multirow[t]{2}{*}{ Child Age Sq. } & -.0828 & -.0924 & $-.1265^{*}$ & -.0197 \\
\hline & $(-1.48)$ & $(-1.46)$ & $(-1.73)$ & $(-.23)$ \\
\hline \multirow[t]{2}{*}{ \# Older Brothers } & $-.0551^{*}$ & -.0381 & $-.0948^{* *}$ & .0033 \\
\hline & $(-1.91)$ & $(-1.2)$ & $(-2.32)$ & $(.08)$ \\
\hline \multirow[t]{2}{*}{ \# Older Sisters } & $.0496^{* * *}$ & $.0513^{* * *}$ & $.0946^{* * *}$ & $.0526^{* *}$ \\
\hline & $(3.22)$ & (3.09) & $(3.88)$ & $(2.53)$ \\
\hline \multirow{2}{*}{$\begin{array}{l}\text { State Fixed Effects } \\
\text { Village Size-Gender Inter. }\end{array}$} & YES & YES & YES & YES \\
\hline & YES & YES & YES & YES \\
\hline \multirow{2}{*}{$\begin{array}{l}\text { Number of Obs. } \\
\mathrm{R}^{2}\end{array}$} & 14132 & 11228 & 8062 & 6070 \\
\hline & .27 & .26 & .28 & .20 \\
\hline \multicolumn{5}{|c|}{$\begin{array}{l}\text { Notes: This table estimates the effect of distance to a primary health center, a community health } \\
\text { center, or a government hospital on the gender imbalance in vaccination. An observation is a } \\
\text { child aged one to four years and the dependent variable is the number of vaccinations the child } \\
\text { has received (0-7). Distance is the minimum distance reported in the village survey to either } \\
\text { a Primary Health Center, a Community Health Center, or a Government Hospital. Column } 1 \\
\text { includes all observations and Column } 2 \text { limits to those without one of these health facilities in } \\
\text { the village. Column } 3 \text { includes all villages, but only people who report wanting equal numbers } \\
\text { of boys and girl or more girls; Column } 4 \text { includes all villages but only those who report wanting } \\
\text { more boys. Other controls: maternal age, maternal education, family income, a dummy for } \\
\text { being Hindu, and birth order. } \\
\text { t-statistics in parentheses, standard errors clustered at the village level } \\
{ }^{*} \text { significant at } 10 \% ;{ }^{* *} \text { significant at } 5 \% ; * * * \text { significant at } 1 \%\end{array}$} \\
\hline
\end{tabular}


Table 7. Regional Relationship Between Levels and Difference in Vaccination

\begin{tabular}{|c|c|c|}
\hline \multicolumn{3}{|c|}{ Dependent Variable: Boy Vacc - Girl Vacc } \\
\hline & (1) & $(2)$ \\
\hline \multicolumn{3}{|l|}{ Explanatory } \\
\hline \\
\hline Average Vacc. & $\begin{array}{l}-.0294 \\
(-1.44)\end{array}$ & $\begin{array}{l}.135^{* *} \\
(2.29)\end{array}$ \\
\hline Average Vacc. Sq. & & $\begin{array}{l}-.0262^{* * *} \\
(-2.97)\end{array}$ \\
\hline Ave. Mother Educ. & $\begin{array}{l}-.013 \\
(-1.07)\end{array}$ & $\begin{array}{l}-.0072^{* * *} \\
(-.59)\end{array}$ \\
\hline Ave. Income (durables) & $\begin{array}{l}.0639 \\
(1.53)\end{array}$ & $\begin{array}{l}.0616 \\
(1.48)\end{array}$ \\
\hline Year & $\begin{array}{l}-.001 \\
(-.07)\end{array}$ & $\begin{array}{l}-.0088 \\
(-.58)\end{array}$ \\
\hline Urban Type & $\begin{array}{l}.1012^{* * *} \\
(3.36)\end{array}$ & $\begin{array}{l}.11 \\
(3.64)\end{array}$ \\
\hline constant & $\begin{array}{l}1.962 \\
(.07)\end{array}$ & $\begin{array}{l}17.231 \\
(.57)\end{array}$ \\
\hline Number of Observations & 3506 & 3506 \\
\hline $\mathrm{R}^{2}$ & .01 & .01 \\
\hline \multicolumn{3}{|c|}{$\begin{array}{l}\text { Notes: This table estimates the relationship between average vaccination } \\
\text { level and gender difference in vaccination. An observation is a cluster in } \\
\text { the survey. The dependent variable is the vaccination average for boys } \\
\text { minus that for girls. The independent variables of interest are the average } \\
\text { vaccination level and that variable squared. These are intended to proxy } \\
\text { for the cost of these investments. } \\
\text { t-statistics in parentheses } \\
{ }^{*} \text { significant at } 10 \% ;{ }^{* *} \text { significant at } 5 \% ;{ }^{* * *} \text { significant at } 1 \%\end{array}$} \\
\hline
\end{tabular}


Table 8. Changes in Gender Bias in Mortality, 1982-1992

Dependent Variable: Child Died 18 months - 5 years

(1)

Low Initial Vaccination
(2) High Initial Vaccination

\begin{tabular}{|c|c|c|}
\hline \multicolumn{3}{|l|}{$\begin{array}{l}\text { Explanatory } \\
\text { Variables: }\end{array}$} \\
\hline Girl $\times$ date of birth & $\begin{array}{l}.00068^{* *} \\
(2.25)\end{array}$ & $\begin{array}{l}-.00088^{* *} \\
(-2.24)\end{array}$ \\
\hline Date of birth (yr) & $\begin{array}{l}-.0004^{*} \\
(-1.72)\end{array}$ & $\begin{array}{l}-.0001 \\
(-.2)\end{array}$ \\
\hline Family Income & $\begin{array}{l}-.005^{* * *} \\
(-9.4)\end{array}$ & $\begin{array}{l}-.0029^{* * *} \\
(-4.84)\end{array}$ \\
\hline Mother Age & $\begin{array}{l}-.0006^{* * *} \\
(-4.15)\end{array}$ & $\begin{array}{l}-.0001 \\
(-.57)\end{array}$ \\
\hline Child Age & $\begin{array}{l}.0001 \\
(.36)\end{array}$ & $\begin{array}{l}-.0006 \\
(-1.31)\end{array}$ \\
\hline Mother Educ. & $\begin{array}{l}-.0004^{* * *} \\
(-3.12)\end{array}$ & $\begin{array}{l}0 \\
(.49)\end{array}$ \\
\hline \# Kids in Family & $\begin{array}{l}.0062^{* * *} \\
(12.8)\end{array}$ & $\begin{array}{l}.0036^{* * *} \\
(6.03)\end{array}$ \\
\hline Number of Observations & 53420 & 14994 \\
\hline \multicolumn{3}{|c|}{$\begin{array}{l}\text { Notes: This table estimates a probit model of the evolution of gender inequality in } \\
\text { mortality over the period from } 1982 \text { to } 1993 \text {, using a created panel based on children } \\
\text { of different ages. The dependent variable is an indicator for whether the child died } \\
\text { between } 18 \text { months and five years, conditional on having reached } 18 \text { months. The } \\
\text { regression is limited to children born five to ten years before the survey. Column } 1 \\
\text { includes states with initially low vaccination levels, where we would expect increases } \\
\text { in gender discrimination over time. Column } 2 \text { includes states with initially high } \\
\text { vaccination levels where we would expect decreases over time. Other controls include } \\
\text { dummies for birth order and region, interacted with girl. The main effect of girl is } \\
\text { not reported since it is captured in the effect for each region. } \\
\text { t-statistics in parentheses } \\
{ }^{*} \text { significant at } 10 \% ;{ }^{* *} \text { significant at } 5 \% ;{ }^{* * *} \text { significant at } 1 \%\end{array}$} \\
\hline
\end{tabular}




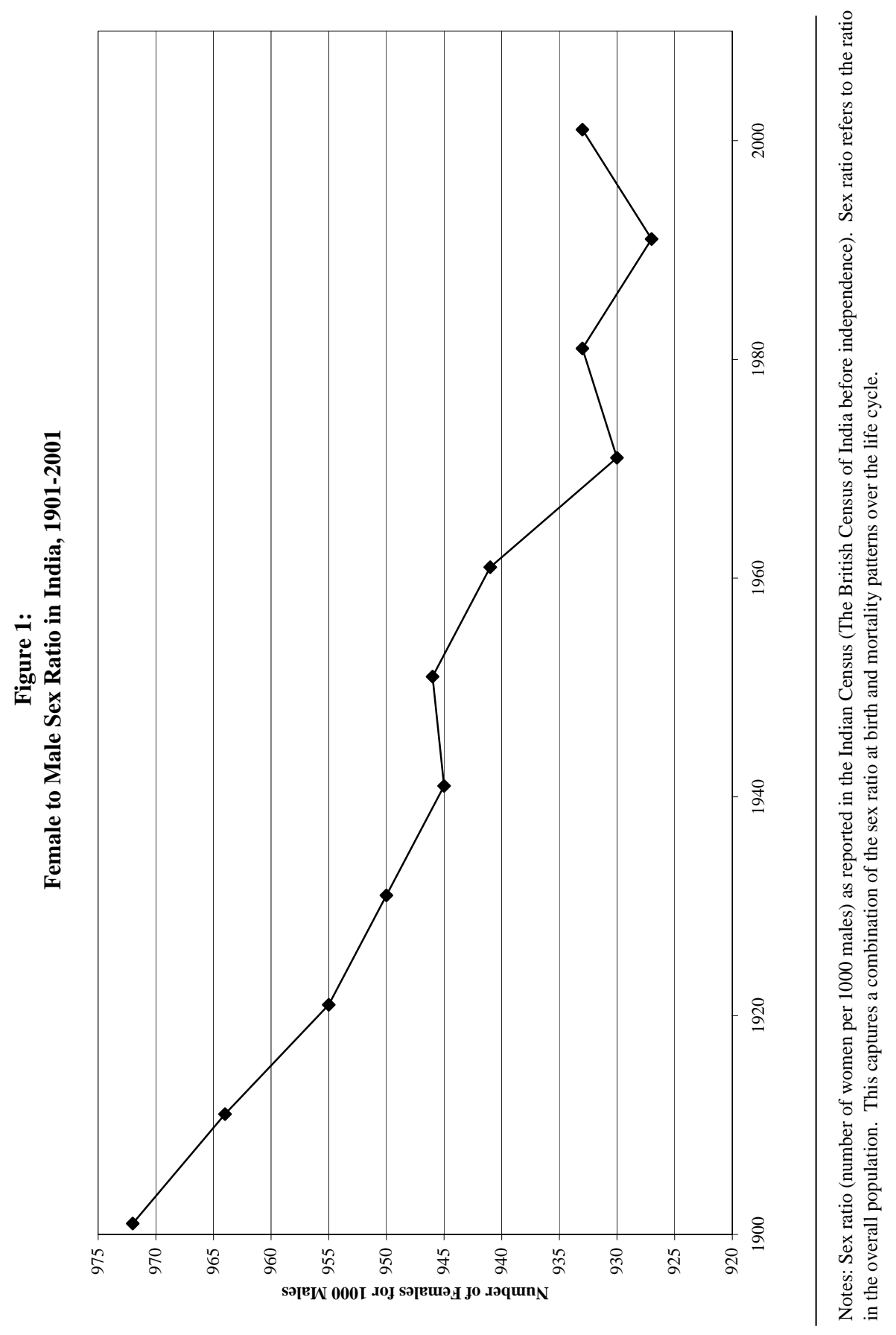




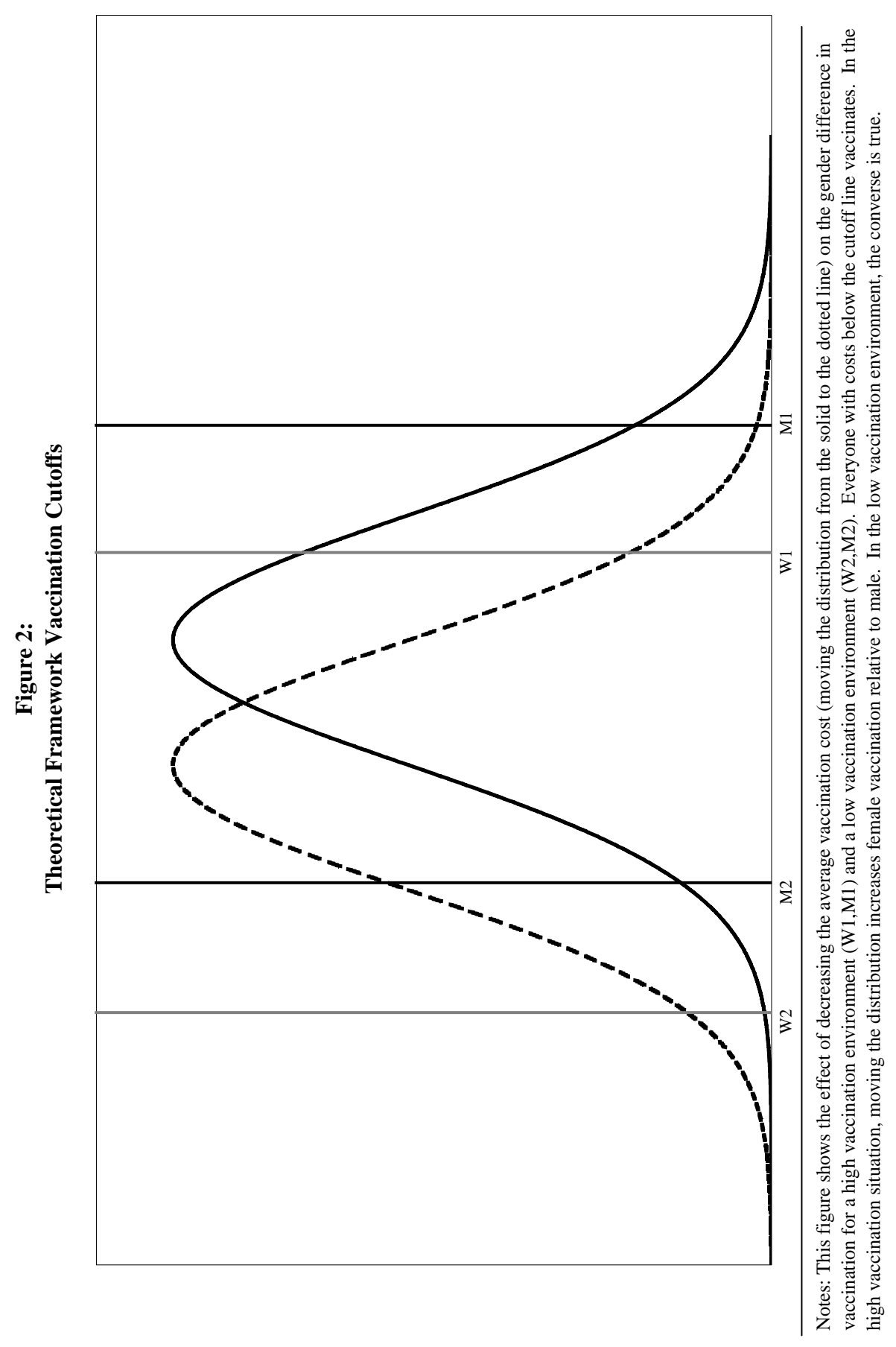




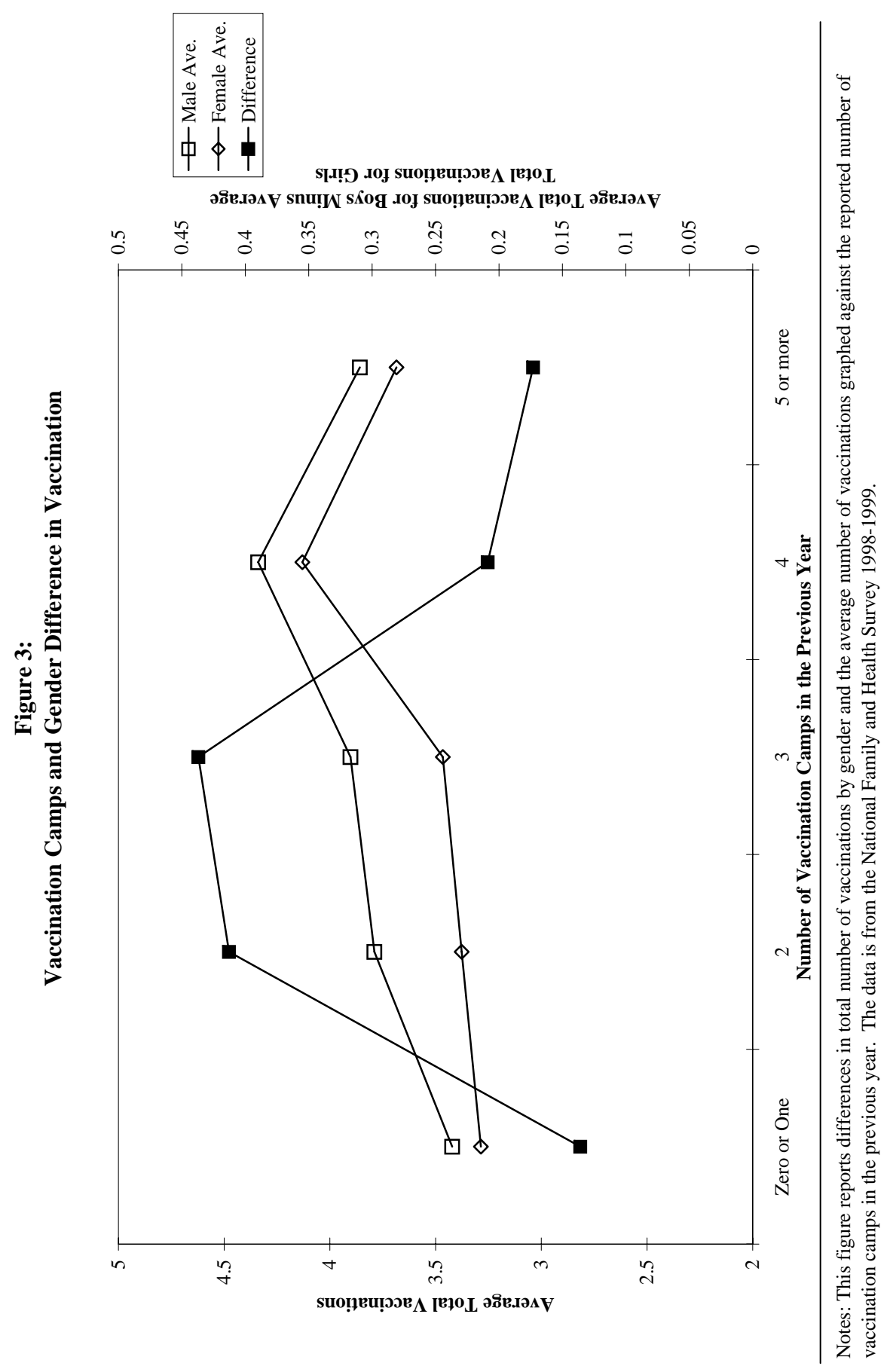




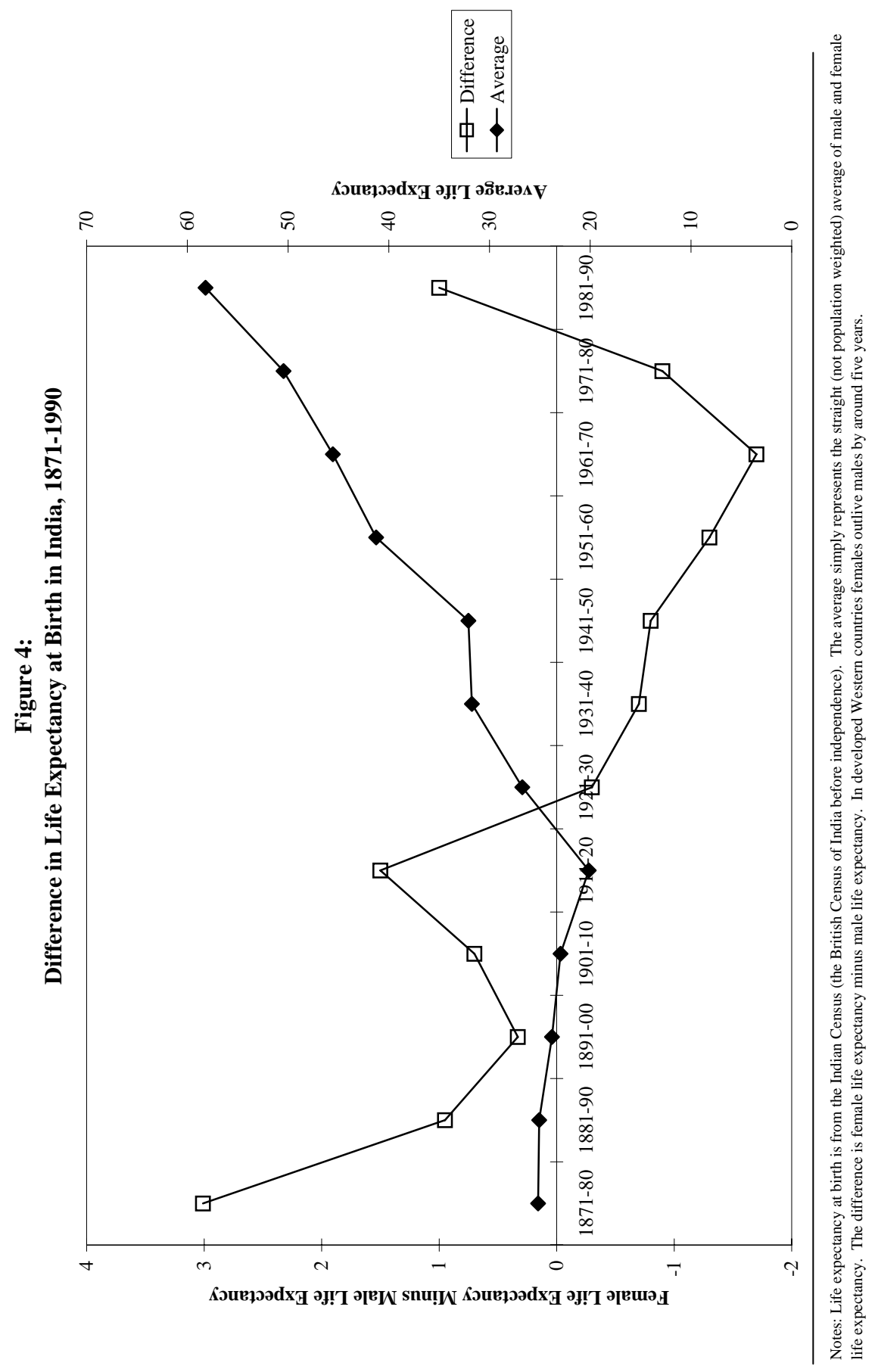

